\title{
Choosing non-oral, long-acting reversible contraception
}

\section{SUMMARY}

Long-acting reversible contraception methods include the copper and hormonal intrauterine devices, the contraceptive implant and the contraceptive injection. These should be discussed with women considering their options for contraception.

These methods are more effective at reducing unintended pregnancy than oral contraceptives and have a good safety profile with few contraindications.

The progestogen-only intrauterine device can be used to manage heavy menstrual bleeding.

\section{Introduction}

Long-acting reversible contraception methods have been underused in Australia but their uptake is now increasing. ${ }^{1}$ Methods include the copper and hormonal intrauterine devices (IUDs), the contraceptive implant and the contraceptive injection. However, the injection is often considered a 'second-tier' method due to its requirement for more frequent administration and therefore lower effectiveness.

There is compelling evidence that women using a shorter acting method such as the oral contraceptive pill are significantly more likely to experience an unintended pregnancy than those using long-acting reversible contraception. ${ }^{2-5}$ An Australian web survey ${ }^{6}$ found that approximately $60 \%$ of women who experienced an unintended pregnancy had been using either condoms or the oral contraceptive pill at the time they conceived.

All long-acting reversible contraception methods can be combined with condoms for women at risk of sexually transmitted infections.

\section{Medical eligibility for long-acting contraception}

Some medical conditions are associated with increased risks when certain contraceptives are used because the contraceptive method adversely affects the condition or because the condition (or its treatment) affects the contraceptive. The World Health Organization developed guidelines for the safe prescribing of contraception. These have been adapted into Medical Eligibility Criteria ${ }^{7}$ which relate to the safety of contraception methods in women with pre-existing medical conditions. This system has four categories (see Box). Table 1 gives the Medical Eligibility Criteria categories for IUDs, and Table 2 gives the categories for the contraceptive implant and contraceptive injection.

\section{Intrauterine devices}

The devices available in Australia are the copper IUDs and the levonorgestrel IUD. Both types are extremely effective and provide immediately reversible contraception. See Table 3 for a comparison of these devices. ${ }^{8}$ IUDs are suitable for women of all ages and parity, and can be used for extended durations in older women (see Table 4). ${ }^{9}$ They can be used by breastfeeding women, those who cannot use oestrogen-containing contraception methods and those on drugs that induce liver enzymes.

Contraindications include current or recent pelvic infections, undiagnosed abnormal vaginal bleeding and significant distortion of the uterine cavity. For the levonorgestrel IUD, a current or past history of breast cancer is also a contraindication. ${ }^{8}$

\section{Box Medical Eligibility Criteria categories for use of contraceptive methods ${ }^{7}$}

Category 1 - a condition for which there is no restriction for the use of the contraceptive method

Category 2 - a condition for which the advantages of using the method generally outweigh the theoretical or proven risks

Category $\mathbf{3}$ - a condition for which the theoretical or proven risks generally outweigh the advantages of using the method. The provision of a method requires expert clinical judgement and/or referral to a specialist contraceptive provider, since the method is not usually recommended unless other more appropriate methods are not available or acceptable

Category $\mathbf{4}$ - a condition that represents an unacceptable risk if the contraceptive method is used

Reproduced under licence from FSRH. (c) Faculty of Sexual and Reproductive Healthcare 2006 to 2016

\section{Mary Stewart}

Senior medical officer Research and Education

\section{Deborah Bateson}

Medical director'

Clinical associate professor ${ }^{2}$

Family Planning NSW

2 University of Sydney

Sydney

\section{Keywords}

contraceptive implant depot contraception, intrauterine

contraception device, medroxyprogesterone acetate

Aust Prescr 2016;39:153-8 http://dx.doi.org/10.18773/ austprescr.2016.057 


\section{Table 1 Medical Eligibility Criteria categories for intrauterine devices in significant medical conditions ${ }^{7}$}

Condition

Category

Copper IUD LNG IUD

Personal characteristics and reproductive history

Postpartum: breastfeeding or non-breastfeeding, including

post-caesarean section

\begin{tabular}{lll}
48 hours to 4 weeks & 3 & 3 \\
\hline Puerperal sepsis & 4 & 4
\end{tabular}

Immediate post-septic abortion

4

4

Cardiovascular disease

Ischaemic heart disease or stroke that develops during use (use of LNG IUD is category 2 and copper IUD is category 1 in

women with pre-existing disease)

\section{Breast and reproductive tract conditions}

Current breast cancer

Previous breast cancer with no evidence of disease for at least 5 years

Unexplained vaginal bleeding (suspicious for serious condition) before evaluation - initiation (use of either method is

1

category 2 if develops during use)

Gestational trophoblastic disease (includes hydatidiform mole, invasive mole and placental tumour) - persistently elevated

beta human chorionic gonadotropin or malignant disease

Cervical cancer awaiting treatment - initiation (use of either method is category 2 if develops during use)

Endometrial cancer awaiting treatment - initiation (use of either method is category 2 if develops during use)

Ovarian cancer awaiting treatment - initiation (use of either method is category 2 if develops during use)

Uterine fibroids, with distortion of the uterine cavity

Distorted uterine cavity (any congenital or acquired uterine abnormality distorting the uterine cavity in a manner that is

incompatible with IUD insertion)

Current pelvic inflammatory disease - initiation (use of either method is category 2 if develops during use)

Chlamydial or gonorrhoeal infection or purulent cervicitis - initiation (use of either method is category 2 if develops during use)

\section{HIV}

HIV infected and using antiretroviral therapy

\section{Gastrointestinal conditions}

Severe (decompensated) cirrhosis

Hepatocellular adenoma and malignant liver tumour

IUD intrauterine device LNG levonorgestrel

Adapted under licence from FSRH. (c) Faculty of Sexual and Reproductive Healthcare 2006 to $2016 .{ }^{7}$

Apart from a small risk of infection in the first three weeks after insertion, modern devices are not associated with an increased risk of future infertility or pelvic infection. Women may experience a vasovagal episode at the time of insertion and there is a small chance of uterine perforation. Expulsion can occur and is more likely within the first year. The management of women presenting with 'missing' IUD threads is outlined in the Figure. ${ }^{10}$

IUDs can be inserted in primary care or in a specialist setting. GPs, and an increasing number of nurses, are being trained to insert these devices. Pregnancy must be excluded before insertion of any IUD.

\section{The levonorgestrel intrauterine device}

The levonorgestrel IUD (Mirena) is a T-shaped plastic intrauterine device with a reservoir of $52 \mathrm{mg}$ of the progestogen levonorgestrel in its stem. The hormone is released slowly into the uterus at a rate of 20 microgram per day over a period of five years. It is subsidised on the Pharmaceutical Benefits Scheme (PBS) for contraception and heavy menstrual bleeding. ${ }^{8}$ The device causes endometrial atrophy, thickens cervical mucus (preventing sperm penetration) and, in some users, prevents or delays ovulation. It may also prevent implantation, ${ }^{11,12}$ and has contraceptive efficacy of $99.8 \%$ in typical and perfect use..$^{13}$ 
Table 2 Medical Eligibility Criteria categories for depot medroxyprogesterone acetate injection and etonorgestrel implants in significant medical conditions ${ }^{7}$

\section{Condition}

Category

DMPA injection ENG implant

Personal characteristics and reproductive history

\begin{tabular}{ll|l}
\hline Postpartum: breastfeeding & Less than 6 weeks & 2 \\
\cline { 2 - 3 } & 6 weeks to 6 months, fully or mostly breastfeeding & 1 \\
\hline Postpartum: non-breastfeeding & 1 & 1
\end{tabular}

\section{Arterial disease and risk factors}

$\begin{array}{lc}\begin{array}{l}\text { Multiple risk factors for cardiovascular disease (e.g. older age, smoking, diabetes, } \\ \text { hypertension and obesity) }\end{array} & 3 \\ \text { Hypertension, with vascular disease } & 3 \\ \text { Past history of ischaemic heart disease, stroke or transient ischaemic attack } & 3 \\ \text { Develops ischaemic heart disease, stroke or transient ischaemic attack during use } & 3\end{array}$

\section{Breast and reproductive tract conditions}

Unexplained vaginal bleeding (suspicious for a serious condition) before evaluation

Current breast cancer

Previous breast cancer with no evidence of disease for at least 5 years

$\begin{array}{ll}3 & 3 \\ 4 & 4 \\ 3 & 3\end{array}$

\section{Gastrointestinal conditions}

Severe (decompensated) cirrhosis

3

Hepatocellular adenoma or malignant liver tumour

DMPA depot medroxyprogesterone acetate ENG etonorgestrel

Adapted under licence from FSRH. (c) Faculty of Sexual and Reproductive Healthcare 2006 to 2016.7

\section{Table 3 Comparison of intrauterine devices ${ }^{8}$}

\begin{tabular}{|c|c|c|}
\hline & $\begin{array}{l}\text { Hormonal intrauterine } \\
\text { device }\end{array}$ & $\begin{array}{l}\text { Copper intrauterine } \\
\text { device }\end{array}$ \\
\hline PBS subsidy & Yes & No (costs $\$ 100)$ \\
\hline \multirow[t]{4}{*}{ Mechanism of action } & May thicken cervical mucus & Toxic to sperm \\
\hline & $\begin{array}{l}\text { Affects sperm/oocyte } \\
\text { motility }\end{array}$ & Endometrial effect \\
\hline & Thins endometrium & \\
\hline & May inhibit ovulation & \\
\hline Duration & 5 years & 5 or 10 years \\
\hline Efficacy & $99.8 \%$ & $99.2 \%$ \\
\hline Effect on bleeding & $\begin{array}{l}\text { Significantly reduces } \\
\text { menstrual bleeding }\end{array}$ & $\begin{array}{l}\text { Can increase menstrual } \\
\text { bleeding and pelvic pain }\end{array}$ \\
\hline $\begin{array}{l}\text { Hormonal adverse } \\
\text { effects }\end{array}$ & Can occur & None \\
\hline Other benefits & $\begin{array}{l}\text { Protects the endometrium in } \\
\text { women requiring hormone } \\
\text { replacement therapy }\end{array}$ & $\begin{array}{l}\text { Provides highly } \\
\text { effective emergency } \\
\text { contraception }\end{array}$ \\
\hline
\end{tabular}

PBS Pharmaceutical Benefits Scheme

\section{Table 4 Duration of use of intrauterine devices in older women ${ }^{9}$}

Age and
circumstances

Age at least

40 years at time of

insertion of a copper

IUD

Can be retained until 1 year after the last menstrual period if this occurs when the woman is over the age of 50 years ( 2 years if under 50 years) (off-label use)

Age at least 45 years at time of insertion of a levonorgestrel IUD

Can use the device for 7 years* or if amenorrhoeic until menopause (offlabel use). After this the IUD should be removed

Age at least 50 years, levonorgestrel IUD, amenorrhoeic If serum follicle-stimulating hormone is at least $30 \mathrm{IU} / \mathrm{L}$ on two occasions 6 weeks apart then remove IUD 1 year later

(determining

menopause)

IUD intrauterine device

* unless being used as part of hormone replacement therapy, in which case the levonorgestrel IUD should be replaced at 5 years 


\section{Fig. Management of a woman with missing intrauterine device threads ${ }^{10}$}

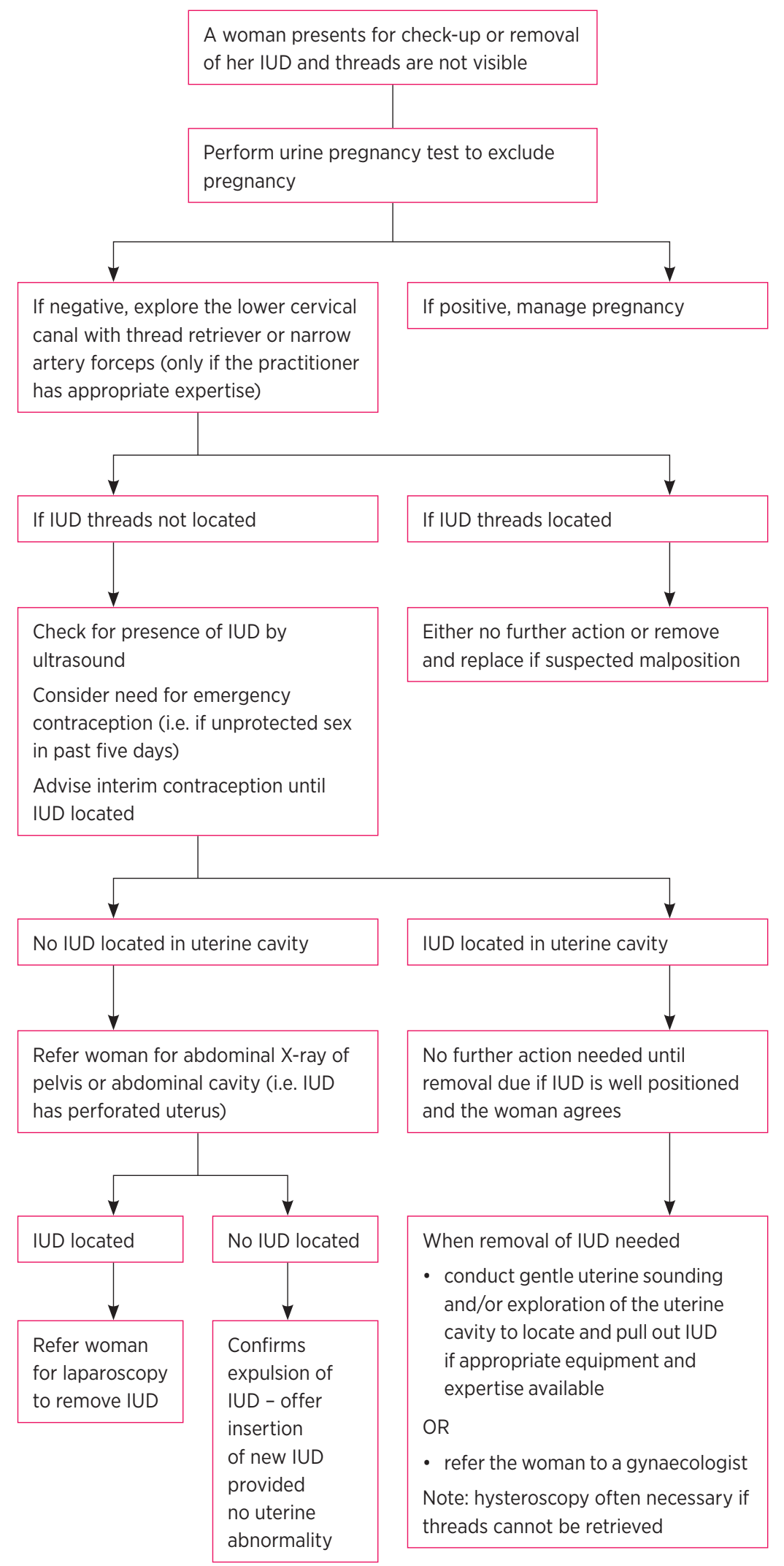

IUD intrauterine device

Adapted with permission from Medicine Today ${ }^{10}$
The levonorgestrel IUD reduces heavy menstrual bleeding significantly and, although frequent spotting or bleeding are common in the first three to five months, most women will establish a pattern of either very light bleeds or amenorrhoea after six months. ${ }^{14,15}$ Due to the very low dose of levonorgestrel absorbed systemically, most women do not experience progestogen-related adverse effects such as headache, breast tenderness or acne.

When inserted within the first seven days of the natural cycle, the levonorgestrel IUD will be effective immediately. However, if put in later in the cycle, another form of contraception or abstinence is recommended for seven days.

\section{The copper intrauterine devices}

There are several types of copper IUDs in Australia. They can be used for different durations:

- TT380 (T-shaped) - can be used for up to 10 years

- TT380 short (T-shaped) - can be used for up to 5 years

- Load 375 - can be used for up to 5 years.

The copper IUDs are not on the PBS and cost approximately $\$ 100$. They are the most effective form of non-hormonal reversible contraception and may be preferred by women who wish to, or need to, avoid hormones. Copper IUDs have a typical use efficacy of $99.2 \% .^{13}$ They can increase menstrual bleeding and dysmenorrhoea. A trial of a non-steroidal anti-inflammatory drug (NSAID) may be a useful management strategy.

Once inserted the copper IUD is immediately effective. It is the most effective form of emergency contraception if inserted within five days of unprotected sex and also has the advantage of providing ongoing, long-term effective contraception.

\section{The contraceptive implant}

The contraceptive implant available in Australia is a single, ethylene vinyl acetate $4 \mathrm{~cm}$ rod containing $68 \mathrm{mg}$ of the progestogen etonorgestrel (Implanon NXT). It is easily implanted directly under the skin of the upper, inner, non-dominant arm using local anaesthetic, by a trained doctor or nurse. The hormone is slowly released over three years. This product is listed on the PBS.

The etonorgestrel implant provides reversible contraception by preventing ovulation, thickening cervical mucus, preventing sperm penetration and possibly preventing implantation by thinning the endometrium..$^{16}$ It is $99.9 \%$ effective in typical and perfect use. ${ }^{13}$

When inserted within the first five days of the natural cycle, the implant will be effective immediately. 
If inserted later in the cycle, another form of contraception is recommended for seven days after insertion.

The implant can be used by most women including those who cannot use oestrogen-containing methods and those with malabsorption. It can be used during breastfeeding but is contraindicated in women with a personal history of, or current, breast cancer (see Table 2).

Concomitant use of drugs that induce liver enzymes, including phenytoin, carbamazepine, St John's wort and rifampicin, increase etonorgestrel metabolism. This potentially decreases the implant's effectiveness and has been associated with implant failure and unintended pregnancies.

The bleeding pattern experienced with the implant is varied and unpredictable. Approximately 3 in 5 women have infrequent, irregular bleeding, 1 in 5 have amenorrhoea, and 1 in 5 have frequent or prolonged bleeding. About half of those with frequent or prolonged bleeding will improve after three months."

Registered medical practitioners are generally required by their insurer to complete the online training program that is provided by the manufacturers (www.implanonnxt.com.au password: implant). Nurses can also be trained to insert the implant providing they meet any medicolegal requirements. A standardised training program for nurses is currently under development.

\section{The contraceptive injection}

The contraceptive injection used in Australia is depot medroxyprogesterone acetate 150 mg (Depo-Provera or Depo-Ralovera) given intramuscularly every 12 weeks. It is listed on the PBS.

The injection works in the same way as the etonorgestrel implant. ${ }^{18}$ Its efficacy is $99.8 \%$ with perfect use and $94 \%$ with typical use (reduced due to the need to return every three months for a repeat injection). ${ }^{13}$

The injection can be used by most women although it is not recommended as first line for women who are under 18 or over 45 , as there is some evidence of a small decrease in bone density. However, this decrease appears to be regained on cessation and has not been shown to increase fracture risk. ${ }^{18}$

The contraceptive injection may be associated with weight gain. ${ }^{18}$ Return to fertility can take 12-18 months so a woman's pregnancy plans need to be considered. ${ }^{19}$

The initial bleeding pattern can include irregular, prolonged or frequent bleeding but up to $70 \%$ of women develop amenorrhoea by 12 months. ${ }^{20-22}$ When the injection is given within the first five days of the natural cycle it will be effective immediately. If given later in the cycle, another form of contraception is recommended for seven days. Pregnancy should be excluded if it is to be given after day five or the injection delayed, if possible, until pregnancy can be excluded. There is no evidence of teratogenesis if the injection is inadvertently given during pregnancy. ${ }^{8}$

\section{Bleeding problems with progestogen-only implant and IUD}

Provide accurate information about expected bleeding patterns when long-acting contraception is initiated. Encouraging review and offering management advice for troublesome bleeding is an important part of contraceptive counselling.

After excluding other causes of irregular bleeding and offering reassurance, medical management can include:

- combined hormonal contraceptive taken continuously or cyclically for three months (if not contraindicated)

- five-day course of an NSAID (e.g. mefenamic acid $500 \mathrm{mg}$ ) 2-3 times a day

- five-day course of tranexamic acid 500 mg twice a day, particularly if bleeding is heavy.

Advise that the implant or IUD can be removed any time and that the contraceptive injection can be discontinued or given at a slightly reduced interval of 10 rather than 12 weeks. ${ }^{23}$

\section{Conclusion}

When it comes to contraception 'one size does not fit all' and women need evidence-based information about the risks and benefits of all methods in order to make the best choice for themselves. Choice is based on a number of factors including medical eligibility, desire for non-contraceptive benefits, experience of adverse effects as well as personal preference. Long-acting reversible contraception methods offer highly effective and cost-effective options for women of all ages. A discussion on the pros and cons of the different options should be a part of consultations about contraception. $<$

Mary Stewart has attended advisory meetings and presented at educational meetings for Bayer Healthcare and MSD as part of her role but has not received personal remuneration for this work.

Family Planning NSW has received sponsorship from Bayer Healthcare and MSD for its educational courses.

Deborah Bateson has attended advisory meetings and presented at educational meetings for Bayer Healthcare and MSD as part of her role but has not received personal remuneration for this work. She has been supported to attend conferences by Bayer Healthcare and MSD.
SELF-TEST QUESTIONS

True or false?

1. St John's wort could potentially decrease the effectiveness of the contraceptive implant.

2. The levonorgestrel intrauterine device can be used to reduce heavy bleeding.

Answers on page 185 


\section{REFERENCES}

1. Family Planning NSW. Reproductive and sexual health: an Australian clinical practice handbook. 2nd ed. Sydney: Family Planning NSW; 2011.

2. NICE National Institute for Health and Care Excellence. Long-acting reversible contraception (update). NICE clinical guideline 30; 2014. www.nice.org.uk/guidance/cg30 [cited 2016 Sep 1]

3. Committee on Comparative Effectiveness Research Prioritization, Institute of Medicine. Initial national priorities for comparative effectiveness research. Washington, DC: National Academies Press; 2009.

4. Baldwin MK, Edelman AB. The effect of long-acting reversible contraception on rapid repeat pregnancy in adolescents: a review. J Adolesc Health 2013;52(Suppl):S47-53. http://dx.doi.org/10.1016/j.jadohealth.2012.10.278

5. Winner B, Peipert JF, Zhao Q, Buckel C, Madden T, Allsworth JE, et al. Effectiveness of long-acting reversible contraception. N Engl J Med 2012;366:1998-2007. http://dx.doi.org/10.1056/NEJMoa1110855

6. Marie Stopes International. Real choices: women, contraception and unplanned pregnancy. Melbourne: Marie Stopes International; 2008.

7. Faculty of Sexual and Reproductive Healthcare. UK medical eligibility criteria for contraceptive use 2009. London: Faculty of Sexual and Reproductive Healthcare; 2009. www.fsrh.org/documents/ukmec-2009 [cited 2016 Sep 1]

8. Bateson D, Harvey C, McNamee K. Contraception: an Australian clinical practice handbook. 3rd ed. Sydney: Family Planning NSW, Family Planning Queensland, Family Planning Victoria; 2012

9. Faculty of Sexual and Reproductive Healthcare clinical guidance. Intrauterine contraception. London: Faculty of Sexual and Reproductive Healthcare; 2015. www.fsrh.org/ documents/ceuguidanceintrauterinecontraception [cited 2016 Sep 1]

10. Harvey C McNamee K, Stewart M. A practical guide to contraception. Part 2: Long-acting reversible methods. Med Today 2013;14:39-51.

11. Xiao B, Zeng T, Wu S, Sun H, Xiao N. Effect of levonorgestrelreleasing intrauterine device on hormonal profile and menstrual pattern after long-term use. Contraception 1995;51:359-65. http://dx.doi.org/10.1016/0010-7824(95)00102-G

12. Xiao BL, Zhou LY, Zhang XL, Jia MC, Luukkainen T, Allonen $\mathrm{H}$. Pharmacokinetic and pharmacodynamic studies of levonorgestrel-releasing intrauterine device. Contraception 1990;41:353-62. http://dx.doi.org/10.1016/ 0010-7824(90)90035-T

13. Trussell J. Contraceptive failure in the United States. Contraception 2011;83:397-404. http://dx.doi.org/10.1016/ j.contraception.2011.01.021
14. Crosignani PG, Vercellini P, Mosconi P, Oldani S, Cortesi I, De Giorgi O. Levonorgestrel-releasing intrauterine device versus hysteroscopic endometrial resection in the treatment of dysfunctional uterine bleeding. Obstet Gynecol 1997;90:257-63. http://dx.doi.org/10.1016/S0029-7844(97)00226-3

15. Díaz J, Faúndes A, Díaz M, Marchi N. Evaluation of the clinical performance of a levonorgestrel-releasing IUD, up to seven years of use, in Campinas, Brazil. Contraception 1993;47:169-75 http://dx.doi.org/10.1016/0010-7824(93)90089-P

16. Faculty of Sexual and Reproductive Healthcare clinical guidance. Progestogen-only implants. London: Faculty of Sexual and Reproductive Healthcare; 2014. www.fsrh.org/ documents/cec-ceu-guidance-implants-feb-2014 [cited 2016 Sep 1]

17. Mansour D, Korver T, Marintcheva-Petrova M, Fraser IS. The effects of Implanon on menstrual bleeding patterns. Eur J Contracept Reprod Health Care 2008;13 Suppl 1:13-28. http://dx.doi.org/10.1080/13625180801959931

18. Faculty of Sexual and Reproductive Healthcare clinical guidance. Progestogen-only injectable contraception. London: Faculty of Sexual and Reproductive Healthcare; 2014. www.fsrh.org/documents/cec-ceu-guidanceinjectables-dec-2014 [cited 2016 Sep 1]

19. Schwallie PC, Assenzo JR. The effect of depomedroxyprogesterone acetate on pituitary and ovarian function, and the return of fertility following its discontinuation: a review. Contraception 1974;10:181-202. http://dx.doi.org/10.1016/0010-7824(74)90073-0

20. Canto De Cetina TE, Canto P, Ordoñez Luna M. Effect of counseling to improve compliance in Mexican women receiving depot-medroxyprogesterone acetate. Contraception 2001;63:143-6. http://dx.doi.org/10.1016/ S0010-7824(01)00181-0

21. Said S, Omar K, Koetsawang S, Kiriwat O, Srisatayapan Y, Kazi A, et al. A multicentered phase III comparative clinical trial of depot-medroxyprogesterone acetate given threemonthly at doses of $100 \mathrm{mg}$ or $150 \mathrm{mg}$ : Il. The comparison of bleeding patterns. World Health Organization. Task Force on Long-Acting Systemic Agents for Fertility Regulation Special Programme of Research, Development and Research Training in Human Reproduction. Contraception 1987;35:591-610. http://dx.doi.org/10.1016/S0010-7824(87)80019-7

22. Sangi-Haghpeykar H, Poindexter AN 3rd, Bateman L, Ditmore JR. Experiences of injectable contraceptive users in an urban setting. Obstet Gynecol 1996;88:227-33. http://dx.doi.org/10.1016/0029-7844(96)00194-9

23. Family Planning Alliance Australia. Guidance for managemen of troublesome vaginal bleeding with progestogen-only long-acting reversible contraception (LARC). Sydney: Family Planning NSW. www.fpnsw.org.au/health-information/ contraception/guidance-management-troublesome-vaginalbleeding-progestogen-only [cited 2016 Sep 1] 